\title{
INFORMATION FOR CONTRIBUTORS
}

\section{SCOPE}

Politics and the Life Sciences (PLS) welcomes new, original research manuscripts that rigorously assess the relationship between biological mechanisms, broadly construed, and political behavior and institutions. The range of appropriate submissions is extraordinarily wide. Potential authors include, but are not limited to, political scientists, psychologists, life scientists, clinicians, health policy scholars, bioethicists, biosecurity and internationalsecurity experts, environmental scientists and ecological economists, moral and evolutionary philosophers, political and environmental historians, communications and public-opinion researchers, and legal scholars.

\section{CRITERIA}

PLS publishes rigorously conducted empirical research, both quantitative and qualitative, that tests clearly articulated theoretical assertions and rigorously argued theoretical essays that are intended to stimulate further scientific research. It employs double-blind peer review in which reviewers are asked to rate a manuscript on several criteria including the worthiness and appropriateness of the subject, the scientific contribution of the manuscript, the rigor of the arguments and analyses, and the overall quality of the manuscript.

To be considered, a submission must not have been published elsewhere, either in whole or in part, or be concurrently under review for publication elsewhere. A manuscript must offer new knowledge or a new understanding of existing knowledge. It must be both "political" and "life-scientific" in its implications, if not in its methods. Scholars of politics must take care to ensure that the life sciences content of their submissions is well-researched and supported, and scholars of the life sciences must take equal care to ensure that the political content of their work is theoretically sound, historically accurate, and philosophically aware.

The editors welcome submission of the following types of manuscripts:

- Research Articles (up to 15,000 words) present novel empirical and/or theoretical findings that are based on rigorously conducted quantitative or qualitative research. Research Articles present complete Introduction, Methods, Results, and Discussion sections.

- Short Reports (up to 5,000 words) present summaries of novel findings that do not meet the level of theoretical and/or empirical contribution expected in Research Articles but do provide advances in research that are likely to stimulate further investigation.

- Meta-Analysis Reports (up to 5,000 words) present rigorously conducted meta-analyses of previous research, both published and unpublished, that are designed to derive conclusions about a well-defined question.
- Replication Reports (up to 5,000 words) present summaries of rigorously conducted replications of previously published research findings.

- Research Tool Reports (up to 5,000 words) introduce and present best practices, innovations, or emerging research methods and techniques that can advance biopolitical research.

- Perspectives (up to 10,000 words) seek to develop and advance in a rigorous, systematic way new theory that is relevant to biopolitical research.

- Book Reviews (1,000-1,500 words) critically inform readers of the contents of a book and the arguments of its author(s). Review Essays (2,000-3,000 words) critically review and integrate the arguments of two or more books. $P L S$ encourages pre-registered studies and registered reports.

\section{REQUIRED ELEMENTS}

Submissions must include the following two documents as separate uploaded files (files can be either MS word, PDF, LaTex, or Zip files):

1. Title Page: The author must attach a separate document containing titling information, which includes the title of the manuscript and one author's full contact information (including email address, telephone number, institutional affiliation, and her or his institutional position [e.g., graduate student, postdoctoral fellow, or Assistant Professor]). It must also include all the names, institutional affiliations, and institutional positions of all co-authors. As well, this document should include Twitter handles for all authors on Twitter, which will be used for publicity if the paper is accepted for publication. Finally, authors should include the word count of the manuscript. The title page, tables, figures, references, keywords, and any online appendices are not included in the word count.

2. Full Manuscript: This document should be anonymized and include the complete manuscript including the manuscript title, an abstract, keywords, the word count, the full body of the text, tables, figures, appendices, and references. The abstract should be a single paragraph of 150 words or less that succinctly describes the research question addressed, the analytical approach, and the major findings. It should exclude references and citations to other work. Manuscript text and appendix materials should be double-spaced in a standard 12-point type font. Other materials, including tables and figures, may be singlespaced using the same font and size used in the body of manuscript. Tables and figures should be included in the manuscript where they are discussed. Explanatory foot- and endnotes are discouraged. All identifying information must be removed from the full manuscript file. This includes acknowledgments of funding, research assistance, or other institutional or personal information that could identify the author(s). Published articles require APAformatted in-text citations and references as well as APA-formatted reports of statistical tests.

\section{ACCEPTED MANUSCRIPTS}

Before publication, all authors will be required to provide a brief disclosure statement concerning possible conflicts of interest. Further, authors using data from human subjects will be required to submit documentation of Institutional or Human Subjects Review Board Approval for their study or, if not possible, an explanation of how they addressed ethical issues in their research. If there are particular issues that required or should have required special ethical consideration because they were beyond minimal risk to the subjects or for other reasons, it will be expected that the authors address these issues in the manuscript itself.

Finally, authors of empirical papers presenting statistical analyses will be strongly encouraged to make appropriate files publicly available for replication purposes.

\section{SUBMISSION}

All submissions to PLS should be made online through ScholarOne at: mc.manuscriptcentral. $\mathrm{com} / \mathrm{pls}$. As part of the submission process, authors will be given the opportunity to suggest possible reviewers, designate keywords, and identify appropriate classifications of the manuscript.

\section{OPEN ACCES POLICIES}

Please visit Cambridge University Press's Open Access page for information on PLS's open access policies, compliance with major finding bodies, and guidelines on depositing your manuscript in an institutional repository. PLS is recognized as a SHERPA/RoMEO green journal.

\section{SUBSCRIPTIONS}

Politics and the Life Sciences is published biannually, in the spring and fall, by Cambridge University Press. Subscriptions are of two types, individual and institutional. For more information or to subscribe, please contact the Cambridge University Press at subscriptions newyork@cambridge.org if you are in the Americas or journals@cambridge.org for the rest of the world.

Annual subscription rates for Volume 38 (2019): institutional subscription rate, print and electronic: \$300; institutional subscription rate, electronic only: \$236; individual subscription rate, print and electronic: $\$ 105$; individual subscription rate, electronic only: $\$ 24$. 


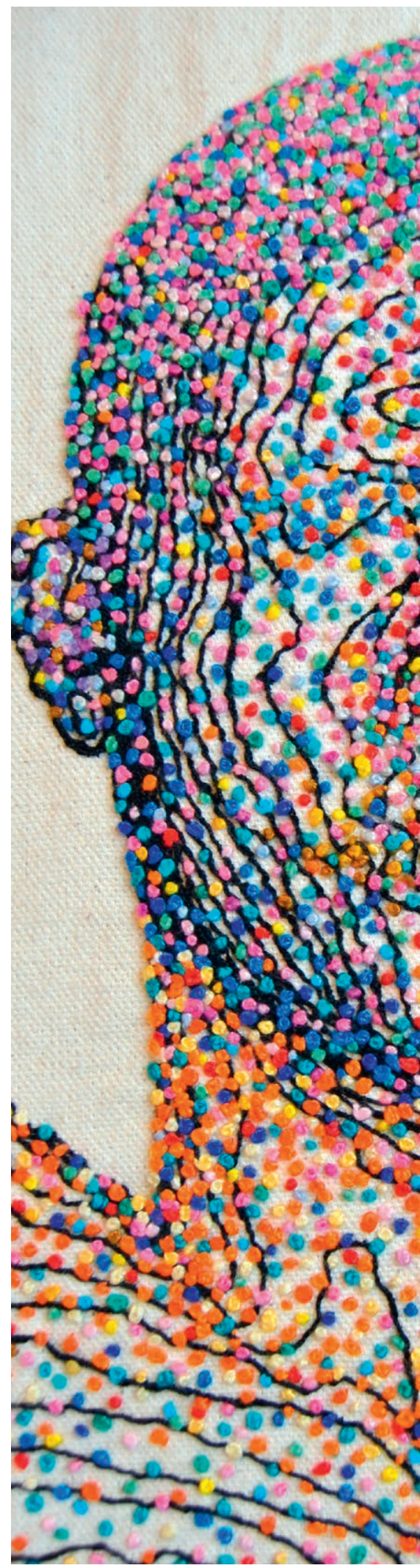

\section{Politics And the Life Sciences}

VOL. 38 , NO. 2

FALL 2019

Welcome to PLS ii

\section{ARTICLES}

Biological approaches to public administration and public policy Introduction

Christopher W. Larimer and Steven A. Peterson

Policies as species

Viewing and classifying policy from an evolutionary biology perspective

Samantha L. Mosier

Doped and disclosed

Anatomopolitics, biopower, and sovereignty in the Russian sports industry

Andrey Makarychev and Sergey Medvedev

Securing Social Security Solvency

Addressing an important social determinant of the health of seniors and the American polity

William P. Brandon and Zachary Mohr

Darwin's bureaucrat

Reassessing the microfoundations of bureaucracy scholarship

Kevin B. Smith and Jayme L. N. Renfro

Torturing science

Science, interrogational torture, and public policy

Shane O'Mara and John Schiemann

180

The role of conspiracy mentality in denial of science and susceptibility to viral deception about science

Asheley R. Landrum and Alex Olshansky

193

The ecology of empire

The dynamics of strategic differentiation-integration in two competing Western European biocultural groups

Aurelio José Figueredo, Mateo Peñaherrera-Aguirre, Heitor Barcellos Ferreira

Fernandes, Sara Lindsey Lomayesva, Michael Anthony Woodley of Menie,

Steven Charles Hertler and Matthew Alexandar Sarraf

\section{Book Reviews}

Robin Dunbar, Human Evolution: Our Brains and Behavior

Reviewed by Arran J. Davis

Ronald Giphart and Mark van Vugt, Mismatch: How Our Stone Age Brain Deceives Us Every Day and What We Can Do about It

Reviewed by Gregg R. Murray

Cass R. Sunstein, On Freedom

Reviewed by Ronald F. White 